\title{
Changes in fundamental frequency depending on language, context, and language proficiency for bilinguals*
}

\author{
Somang Yoon · Sora Mok · Jungseon Youn · Jiyun Han · Dongsun Yim** \\ Department of Communication Disorders, Ewha Womans University, Seoul, Korea
}

\begin{abstract}
The purpose of this study is to determine whether the mean fundamental frequency (F0) changes depending on language, task, or language proficiency for Korean-English bilinguals. A total of forty-eight Korean-English speakers (28 balanced bilinguals and 20 Korean dominant bilinguals) participated in the study. Participants were asked to read aloud two types of tasks in English and Korean. For statistical analyses, the language $\times$ task two-way repeated ANOVAs were conducted within the balanced bilingual group first, and then group $\times$ language two-way mixed ANOVAs. The results showed that the females in both bilingual groups changed their mean F0 depending on the language they used and the tasks $(p<.05)$, whereas no significant results were found in the males in either group under any conditions. The mean fundamental frequency in the Korean reading task was significantly higher than that in the English reading task for females in both balanced and Korean dominant bilingual groups. Thus, changes in mean F0 depending on language and context may reflect gender-specific characteristics, and females seem to be more sensitive to the socio-cultural standards that are imposed on them.
\end{abstract}

Keywords: bilingual, cross-linguistic, voice difference, mean fundamental frequency, mean F0

\section{1. 서론}

사람들은 기본적으로 고유의 목소리를 지니고 있으며 각자 의 목소리 음역대 안에서 각기 다른 음도(pitch)를 가진다(Chen, 2005; Dolson, 1994; Eady, 1982). 이러한 음도는 1초 동안의 성 대(vocal cords)가 진동하는 횟수인 기본주파수(fundamental frequency, F0)로 표현한다. 기본주파수는 해부-생리학적 변화에 의
하여 성대의 길이, 크기, 긴장에 따라 달라진다. 성대의 길이가 짧고 크기가 작을수록, 긴장도가 높을수록 기본주파수가 높아 지는데(Fucci \& Lass, 1999; Ohala, 1984; Laver, 1980), 성별 및 연 령에 따른 기본주파수의 차이는 주로 성대의 크기와 길이의 차 이로 설명된다. 보통 사춘기 이전에는 남녀 간 기본주파수의 차 이는 보이지 않다가 사춘기 이후부터 남성의 후두가 커지고, 성 대는 길고 굵어지면서 여성보다 기본주파수가 낮아지게 된다.

\footnotetext{
* This work was supported by the Ministry of Education of the Republic of Korea and the National Research Foundation of Korea (NRF-2018S1A3A2075274). ** sunyim@ewha.ac.kr, Corresponding author

Received 15 February 2019; Revised 4 March 2019; Accepted 14 March 2019

(C) Copyright 2019 Korean Society of Speech Sciences. This is an Open-Access article distributed under the terms of the Creative Commons Attribution NonCommercial License (http://creativecommons.org/licenses/by-nc/4.0) which permits unrestricted non-commercial use, distribution, and reproduction in any medium, provided the original work is properly cited.
} 
그러나 점차 중 - 장년기에 접어들면서 남성은 일반적으로 성대 가 가늘어지며 기본주파수가 증가하고, 여성 또한 호르몬의 변 화로 성대는 더욱 무거워져 기본주파수는 감소한다(Hollien \& Shipp, 1972; Morrison \& Gore-Hickman, 1986; Mysak, 1959).

연령과 더불어 사용하는 언어에 따라 기본주파수가 달라지 기도 한다(Mennen et al., 2012; Traunmüller \& Eriksson, 1995; Van Bezooijen, 1995). 특히, 이중언어 화자를 대상으로 한 연구에서 한 화자 안에서도 언어에 따라 기본주파수가 변화한다는 결과 가 학계에 지속적으로 보고되고 있다(Graham, 2014). Hanley et al.(1966)의 연구에 의하면 스페인어, 일본어, 영어를 모국어로 쓰는 남성 화자들을 대상으로 각각의 언어로 된 읽기 자료와 발 화 표본을 분석하여 동일한 화자의 기본주파수가 언어에 따라 달라지는지 살펴보았다. 그 결과, 영어, 일본어, 스페인어 순으 로 기본주파수 범위가 더 컸다고 보고하였다. 또한 Andreeva et al.(2014)은 영어 및 독일어 화자를 게르만어군(Germanic group) 으로 묶고, 불가리아어, 폴란드어 화자를 슬라브어군(Slavic group) 으로 나누어 두 집단 간 기본주파수 차이를 비교하였다. 그 결 과, 게르만어군 화자의 기본주파수가 슬라브어군 화자들의 기 본주파수 평균보다 낮았으며 기본주파수의 범위도 슬라브어군 이 게르만어군보다 더 컸다고 하였다. 그리고 Yuan(2014) 연구 에서는 미국 영어(American English) 화자와 만다린어(Mandarin Chinese) 화자의 실제 뉴스 말뭉치 자료를 분석하여 두 언어 간 기본주파수 범위의 차이를 살펴보았다. 그 결과, 만다린어 화자 의 기본주파수 평균이 영어 화자보다 높았으며 주파수 범위 격 차는 만다린어 화자가 영어 화자보다 큰 것으로 나타났다. 특히, Ryabov et al.(2016)에서 영어-러시아어 이중언어 화자를 대상으 로 연결 발화를 분석한 결과, 언어의 능숙도 및 거주년수, 이민 시기 등이 각기 달랐음에도 불구하고, 언어 간 평균 기본주파수 변화가 뚜렷하게 나타났다고 보고했다. 또한 Nevo et al.(2015)의 연구에서도 영어-히브리어를 모두 능숙하게 사용하는 이중언 어 화자가 하나의 주제에 대해 이야기를 했을 때, 히브리어보다 영어의 평균기본주파수가 더 높은 것으로 나타났다. 즉, 같은 화 자더라도 사용하는 언어에 따라 자신의 음도를 조절한다는 것 을 의미한다.

기본주파수는 언어에 따라 다르다는 연구가 진행됨에 따라 (Chen, 2005; Dolson, 1994; Eady, 1982; Keating \& Kuo, 2012), 이 를 규명하기 위해 다양한 이론들이 제시되었다. 첫 번째는, 해 부생리학적 차이(Künzel, 1989; Van Dommelen \& Moxness, 1995) 가 언어 간 기본주파수 차이의 원인이라고 주장하는 이론으로 해당 언어를 구사하는 사람들 간의 해부생리학적 차이로 인해 주파수가 달라진다는 것이다. 그러나 동일한 이중언어 화자의 언어 간 기본주파수 변화를 살펴본다면 해부생리학적 요인으 로 이러한 변화를 설명하기 어려울 것이다. 두 번째로, 행태학적 (ethological)인 요인에 의해서 달라진다는 주장인데, Ohala(1984) 는 기본주파수는 내재된 특정한 주파수 코드를 참조하며 설명 할 수 있다고 했다. 이 주장에 따르면 고유하게 저장된 생물학 적인 코드는 후두 크기와 성대 진동의 비율 사이의 상관관계 를 기반으로 하므로 작은 후두가 큰 후두보다 높은 기본주파수
를 생성한다고 주장하였다. 즉, 높은 주파수는 작은 화자(small vocalizer)를 의미하며, 그들의 음성을 순종적이고 취약한 것으 로 연결하고, 낮은 주파수는 큰 화자(large vocalizer)를 의미하여 그들의 음성을 우세하고 위협적인 것으로 연결시켰다. 이러한 상관관계는 일반적으로 구어에서 권력 관계를 표현하기 위해 이용된다고 하며, 만일 기본주파수가 그러한 행태학적인 요인 에 의해서만 결정된다면 이러한 요소들이 두 언어에서 유사하 게 나타날 것으로 예상된다. 세 번째로, 언어마다 서로 다르게 나타나는 음운론적 특성이 주파수범위에 영향을 미친다는 주 장도 있다(Mennen et al., 2012; Yamazawa \& Hollien, 1992). 예 를 들어, 유성자음은 같은 유성자음 뒤에 연속할 때보다 무성 자음 뒤에 위치할 때 더 높은 기본주파수 값을 보인다고 하는데 (Gussenhoven, 2004), 이러한 특성들이 언어마다 다르기 때문에 기본주파수에서 차이가 나타난다는 것이다. 마지막으로, 해당 언어권의 사회문화적인 차이가 원인이라는 주장이다. 이는 언 어적 배경과 관련된 언어 외적인 요인에 따라 일부는 언어 간 주파수 범위를 변화시킬 것이고 다른 일부는 그렇지 않을 수 있 다고 하는 주장으로 사회문화적 요인에 따라 기본주파수의 영 향을 줄 수 있다고 하였다(Deutsch et al., 2009; Dolson, 1994; Van Bezooijen, 1995).

주목할 만한 것은 이중언어 화자를 대상으로 하는 많은 연구 에서 성별과 언어에 따른 기본주파수 차이를 사회문화적인 관 점에서 해석한다는 것이다(Ohara, 1999; Ordin \& Mennen, 2017; Voigt et al., 2016). 예를 들어, Ohara(1999)는 영어-일본어 이중언 어 화자의 기본주파수 범위를 연구한 결과, 여성의 일본어-영어 사용에 있어서 기본주파수 범위에 유의한 변화가 있다는 것을 확인하였다. 그리고 이러한 차이가 여성에서만 나타난 이유를 언어의 운율적 특징 차이보다는 사회 문화적인 영향과 관련되 어 있다고 주장했다. Ordin \& Mennen(2017)도 영어-웨일즈어 이 중언어 화자의 말을 분석한 결과 여성의 경우에만 기본주파수 범위 차이가 있었다는 결과를 보고한 바, 이는 언어 배경과 언어 공동체의 사회 문화적 요인을 반영한 결과로 보인다. Ordin \& Mennen(2017)은 여성의 경우에서만 변화가 나타난 것을 두고, 남성과 여성이 추구하는 바의 차이로 설명하고 있다. 즉, 남성의 경우 그들 본인의 개성을 중시하는데 비해 여성은 사회 규범과 본인의 인격을 적절하게 균형을 맞춰나가려는 경향이 만들어 낸 결과라고 추측하고 있다. 그러나 이러한 배경에는 남성에게 는 더 경쟁적이고 독립적인 인격을 요구하고 여성에게는 더 협 력하도록 하는 사회의 분위기가 반영된 것이라고도 볼 수 있다 (Barrett et al., 1993; Bussey \& Bandura, 1999; Eagly, 1978; Huston, 1983). 이처럼 이중언어 화자를 대상으로 한 최근의 연구들은 언어 간 기본주파수 변화의 원인에 대해 사회문화적인 요소를 중요하게 지적한다. 언어는 화자가 속한 문화와 경험으로 얻은 개인의 정체성의 상호작용으로 이루어지는 것으로 사회적 배 경이 목소리 변화에 영향을 줄 수 있다는 생각에 기초한 해석인 것이다(Briley et al., 2005; Danziger \& Ward, 2010; Ellis et al., 2015; Ogunnaike et al., 2010; Ordin \& Mennen, 2017).

이에 두 언어를 사용하는 이중언어 화자를 대상으로 사용하 
는 언어에 따라 기본주파수와 같은 음향학적 지표 변화를 살펴 보는 것은 음도변화의 기전을 살펴볼 수 있다는 점에서 중요하 다. 예를 들어, 기본주파수 변화가 화자의 해부 생리적 차이나 행태학적 차이에 기인한다면 이중언어 화자가 두 언어를 사용 할 때 기본주파수의 변화는 나타나지 않아야 한다. 그러나 만약 사용하는 언어의 특성에 따라 기본주파수가 변화한다면, 이중 언어 화자의 사용언어에 따라 기본주파수가 변화할 것이다. 또 한, 사회문화적 요인에 의한 것이라면 문화적 배경이 다른 집단 마다 기본주파수가 다르게 나타날 수 있을 것이다. 따라서 본 연 구에서는 선행연구 결과를 기반으로 언어(Chen, 2005; Deutsch et al., 2009)와 사회적 집단(Awan \& Mueller, 1996; Dolson, 1994; Graddol \& Swann, 1983; Van Bezooijen, 1995)이 기본주파수에 영 향을 미치는 주요 변인으로 하여 한국어-영어 이중언어 화자를 대상으로 기본주파수가 성별, 사용언어, 사회적 집단에 따라 달 라지는지 알아보고자 한다. 기존 연구에서는 사회적 집단을 문 화적 배경을 바탕으로 나누었으나 본 연구에서는 성별 및 문화 권을 경험한 기간인 거주년수와 경험을 통해 습득한 언어의 능 숙도에 초점을 두고 분류하였다. 음도변화는 사회문화적 요인 에 기인한다고 가정하였을 때, 사회문화적 특성에 더 민감하게 반응하는 여성에게서 사용언어에 따른 기본주파수 변화가 나 타날 것이라고 기대한다. 다시 말해, 여성은 영어-한국어 발화 에서 기본주파수 범위에 차이를 보이지만, 남성의 경우에는 차 이를 보이지 않을 것으로 예상하였다.

또한 기본주파수는 성별과 언어에 이어 과제조건에 따라서 도 변할 수 있다(Hollien et al., 1997; Shrivastav et al., 2000; Zraick et al., 2000). Murry et al.(1995)은 연장발성 및 읽기, 즉흥적인 자 발화 조건에 따른 평균 기본주파수를 조사한 결과, 남성 화자는 읽기 상황이나 자발화 상황에서의 기본주파수가 연장발성에서 보다 유의하게 높았으며 여성의 경우에는 연장발성이 더 유의 하게 높은 것으로 나타났다고 보고하였다. Zraick et al.(2000)의 연구에서는 연장발성, 읽기, 숫자세기 등 다양한 과제를 통해 평균 기본주파수를 측정하였을 때, 아동 및 성인 남성의 평균 기본주파수는 과제 간 유의한 차이가 없었으나 여성에게서는 유의한 차이가 나타났다고 보고하였다. 그러나 이중언어 화자 의 음도 변화에 대해 살펴본 기존 연구들은 읽기 상황에서의 목소리 변화를 살펴본 것이 대부분이다(Lim et al., 2016; Ordin \& Mennen, 2017).

언어적 능숙도 또한 기본주파수에 영향을 줄 수 있다. Busà \& Urbani(2011)의 연구에서는 이탈리아어 화자에게 영어로 질문 에 답하도록 한 결과, 영어가 모국어인 집단의 발화에 비해 이 중언어 화자의 기본주파수 범위가 더 작은 것으로 나타났다. Zimmerer et al.(2014)은 프랑스어, 독일어가 모국어인 화자들은 모국어인 L1(First language, 또는 Mother tongue)의 발화보다 두 번째 언어인 L2(Second language)의 발화에서 더 작은 기본주파 수 범위를 보였다고 보고하였는데, 이는 발화 시 그들이 초분절 적인 특징보다는 단어의 분절화에 더 초점을 맞추는 것과 더불 어 L1에 비해 L2를 사용할 때 자신감이 떨어지기 때문이라고 해 석했다. 따라서 L2를 얼마나 자연스럽고 능숙하게 사용할 수 있
는지에 따라서도 차이가 따라서 언어의 능숙도가 음향적인 지 표에 영향을 줄 수 있다고 생각할 수도 있다. 하지만, 이중언어 화자의 각 언어별 노출기간에 따른 언어 간 기본주파수 변화의 양상을 확인한 연구는 제한적이다.

따라서 본 연구에서는 이중언어 화자들이 사용하는 언어와, 언어별 능숙도에 따라 다양한 상황에서 기본주파수가 변화하 는지 알아보고자 하였다. 특히, 한국어-영어 이중언어 화자를 대상으로 읽기 상황뿐 아니라, 일상적인 질문에 답하는 자발화 상황에서도 읽기상황과 마찬가지로 평균 기본주파수가 달라지 는지를 살펴보고자 하였다. 앞선 선행연구에서 보고한 바와 같 이 과제 유형에 따라 화자의 기본주파수가 달라진다면(Hollien et al., 1997; Murry et al., 1995; Zraick et al., 2000) 기본주파수는 읽 기 상황과 자발화 상황에 따라 달라질 것이며, 사용하는 언어에 따라서도 다르게 나타날 것으로 예상한다. 또한, 만약 사용하는 언어에 따라 이중언어 화자들의 기본주파수 범위가 변화한다 면 각 언어를 사용한 기간과 언어의 능숙도에 따라서도 기본주 파수가 달라질 것이다. 그러므로 이중언어 화자의 언어 능숙도 및 노출기간에 따라 집단을 나누어 두 언어 간 기본주파수의 차 이를 비교한다면 두 언어에 대한 능숙도가 높을수록 기본주파 수 범위의 변화가 클 것으로 예상한다.

따라서 본 연구의 연구 질문은 다음과 같다.

1) 균형적 이중언어 화자의 평균 기본주파수가 언어(한국어, 영어) 및 과제(읽기, 자발화)에 따라 유의하게 달라지는가?

2) 읽기 과제에서 집단 간(균형적 이중언어 집단 vs. 한국어 우세 이중언어 집단) 평균 기본주파수가 언어(한국어, 영 어)에 따라 유의하게 달라지는가?

\section{2. 본론}

\section{1. 대상자}

본 실험은 연구 질문에 따라 두 가지 실험단계로 나누어서진 행하였다. 먼저 첫 번째 연구 질문을 검증하기 위한 대상자는 영어를 L1으로 사용하는 국가에서 7년 이상 거주한 경험이 있 는 균형적 이중언어 집단으로 20-30대 한국어-영어 이중언어 화 자 28명(남 14명, 여 14명)으로 하였다. 이들은 한국어와 영어에 모두 능숙한 사람이었다.

또한, 두 번째 연구 질문에 따라 균형적 이중언어 집단의 대 상자와 언어 노출기간 및 능숙도에 차이를 두고 비교하고자 20-30대 한국어-영어 이중언어 화자 20명(남 10명, 여 10 명)을 추가로 모집하였으며(한국어 우세 이중언어 집단), 본 대상자들 은 영어를 L1으로 사용하는 국가에서 6개월 이상, 3 년 미만으로 거주한 경험이 있고 한국어를 모국어로 하는 이중언어 화자로 선정하였다.

이후 전체 대상자에게 자기보고식 설문지 Leap-Q(Marian et al., 2007)를 작성하여 각 언어별 능숙도를 보고하게 하였다. 각 대상자 집단의 평균 나이 및 각 언어권 국가에서의 거주년수 및 언어 능숙도 점수는 표 1에 제시하였다. 
표 1. 대상자 배경정보

Table 1. Participants' characteristics

\begin{tabular}{|c|c|c|c|c|c|c|c|c|c|c|c|c|c|}
\hline \multirow{2}{*}{ Group } & \multirow{2}{*}{ Gender } & \multirow{2}{*}{$\begin{array}{l}\text { Age } \\
\text { (yrs) }\end{array}$} & \multirow{2}{*}{$\begin{array}{c}\text { Years of } \\
\text { education } \\
(y r s)\end{array}$} & \multicolumn{2}{|c|}{$\begin{array}{c}\text { Length of } \\
\text { residence(yrs) }\end{array}$} & \multicolumn{4}{|c|}{$\begin{array}{l}\text { English proficiency* } \\
\text { (Raw scores) }\end{array}$} & \multicolumn{4}{|c|}{$\begin{array}{l}\text { Korean proficiency* } \\
\text { (Raw scores) }\end{array}$} \\
\hline & & & & English & Korea & $\begin{array}{l}\text { Expres- } \\
\text { sion }\end{array}$ & \begin{tabular}{|c|} 
Compre- \\
hension
\end{tabular} & Reading & Mean & $\begin{array}{c}\text { Expres- } \\
\text { sion }\end{array}$ & $\begin{array}{l}\text { Compre- } \\
\text { hension }\end{array}$ & Reading & Mean \\
\hline \multirow{2}{*}{$\begin{array}{l}\text { Balanced } \\
\text { bilinguals }\end{array}$} & $\begin{array}{l}\text { Women } \\
(n=14)\end{array}$ & $\begin{array}{l}27.14 \\
(4.22) \\
\end{array}$ & $\begin{array}{l}16.14 \\
(2.16) \\
\end{array}$ & $\begin{array}{l}11.85 \\
(4.22) \\
\end{array}$ & $\begin{array}{l}14.57 \\
(6.84) \\
\end{array}$ & $\begin{array}{c}9.00 \\
(0.92) \\
\end{array}$ & \begin{tabular}{|c|}
9.07 \\
$(0.70)$ \\
\end{tabular} & $\begin{array}{c}8.92 \\
(0.88) \\
\end{array}$ & $\begin{array}{c}9.00 \\
(0.84) \\
\end{array}$ & $\begin{array}{c}9.00 \\
(1.25) \\
\end{array}$ & $\begin{array}{c}9.00 \\
(1.30) \\
\end{array}$ & $\begin{array}{c}9.07 \\
(1.22) \\
\end{array}$ & $\begin{array}{c}9.02 \\
(1.26)\end{array}$ \\
\hline & $\begin{array}{c}\text { Men } \\
(n=14)\end{array}$ & $\begin{array}{l}25.93 \\
(2.09)\end{array}$ & $\begin{array}{l}15.64 \\
(1.59) \\
\end{array}$ & $\begin{array}{l}11.71 \\
(4.10) \\
\end{array}$ & $\begin{array}{l}14.07 \\
(4.43) \\
\end{array}$ & $\begin{array}{c}8.36 \\
(1.34) \\
\end{array}$ & $\begin{array}{c}8.93 \\
(0.96) \\
\end{array}$ & $\begin{array}{c}8.86 \\
(0.64) \\
\end{array}$ & $\begin{array}{c}8.71 \\
(1.05) \\
\end{array}$ & $\begin{array}{c}8.57 \\
(1.68) \\
\end{array}$ & $\begin{array}{c}8.43 \\
(1.76) \\
\end{array}$ & $\begin{array}{c}8.71 \\
(1.44) \\
\end{array}$ & $\begin{array}{r}8.57 \\
(1.64) \\
\end{array}$ \\
\hline \multirow{2}{*}{$\begin{array}{c}\text { Korean } \\
\text { dominant } \\
\text { bilinguals }\end{array}$} & $\begin{array}{l}\text { Women } \\
(\mathrm{n}=10)\end{array}$ & $\begin{array}{l}25.80 \\
(1.83) \\
\end{array}$ & $\begin{array}{l}16.25 \\
(0.51) \\
\end{array}$ & $\begin{array}{c}1.04 \\
(0.72) \\
\end{array}$ & $\begin{array}{l}24.90 \\
(2.04) \\
\end{array}$ & $\begin{array}{c}5.70 \\
(2.33) \\
\end{array}$ & $\begin{array}{c}6.90 \\
(2.21) \\
\end{array}$ & $\begin{array}{c}7.00 \\
(2.24) \\
\end{array}$ & $\begin{array}{c}6.53 \\
(2.33) \\
\end{array}$ & $\begin{array}{c}9.80 \\
(0.60) \\
\end{array}$ & $\begin{array}{c}9.80 \\
(0.40) \\
\end{array}$ & $\begin{array}{c}9.90 \\
(0.30) \\
\end{array}$ & $\begin{array}{c}9.83 \\
(0.45) \\
\end{array}$ \\
\hline & $\begin{array}{c}\text { Men } \\
(n=10)\end{array}$ & $\begin{array}{l}25.70 \\
(2.97)\end{array}$ & $\begin{array}{l}14.20 \\
(1.60)\end{array}$ & $\begin{array}{c}1.47 \\
(0.94)\end{array}$ & $\begin{array}{l}24.28 \\
(2.34)\end{array}$ & $\begin{array}{c}6.20 \\
(1.94)\end{array}$ & $\begin{array}{c}6.60 \\
(1.80) \\
\end{array}$ & $\begin{array}{c}6.50 \\
(1.86) \\
\end{array}$ & $\begin{array}{c}6.43 \\
(1.87) \\
\end{array}$ & $\begin{array}{c}9.10 \\
(0.94)\end{array}$ & $\begin{array}{c}9.10 \\
(1.04)\end{array}$ & $\begin{array}{c}9.30 \\
(0.90)\end{array}$ & $\begin{array}{c}9.17 \\
(0.97)\end{array}$ \\
\hline
\end{tabular}

Values are presented as mean.

* LEAP-Q (Marian et al, 2007).

균형적 이중언어 집단과 한국어 우세 이중언어 집단 간 거주 년수 및 언어 능숙도, 연령, 교육년수에 유의한 차이가 있는지 살펴보기 위해 독립표본 $t$-검정을 실시하였다. 그 결과, 집단 간 한국어권 $\left(t_{46}=-7.410, p=.001\right)$ 및 영어권 거주년수 $\left(t_{46}=10.913\right.$, $p=.000)$ 는 통계적으로 유의한 차이가 있었다. 즉, 균형적 이중언 어 집단 $(M=11.78(\mathrm{yrs}), S D=4.24)$ 이 한국어 우세 이중언어 집단 $(M=1.26(\mathrm{yrs}), S D=.89)$ 보다 영어권 국가에서 더 오래 거주하였 다. 또한, 영어 이해 $\left(t_{46}=5.167, p=.001\right)$ 및 읽기 $\left(t_{46}=4.905, p=.001\right)$, 표현 $\left(t_{46}=5.480, p=.010\right)$ 능력에서 각각 유의한 차이를 나타내 두 집단 간 영어 능숙도에 유의한 차이를 보였다. 즉, 균형적 이중언어 집단 $(M=9.00, S D=.86)$ 은 한국어 우세 이중언어 집단 $(M=6.750, S D=2.07)$ 보다 영어 이해에서 높은 능숙도를 보이고, 읽기에서도 균형적 이중언어 집단 $(M=8.89, S D=.79)$ 이 한국어 우 세 이중언어 집단 $(M=6.75, S D=2.12)$ 보다 높은 능숙도를 보였으 며, 표현에서도 균형적 이중언어 집단 $(M=8.68, S D=1.22)$ 이 한국 어 우세 이중언어 집단 $(M=5.95, S D=2.21)$ 의 것보다 높았다. 반 면, 연령 및 교육년수는 두 집단 간 통계적으로 유의한 차이가 없었다.

\section{2. 연구도구}

본 연구에서는 읽기 상황과 자발화 상황에서의 평균 기본주 파수를 측정하였다. 본 연구에서 사용한 읽기 과제는 길이와 난 이도가 비슷하며, 중립적인 내용으로 구성된 글을 인터넷 뉴스 를 통해 수집하였고, 과제의 타당도를 검증하기 위해 내용타 당도를 분석하였다. 내용타당도를 살펴보기 위해 한국어와 영 어가 모두 유창하다고 보고한 3 인의 이중언어 화자에게 4점 척 도의 설문지를 배포 및 회수하여 분석하였다. 내용타당도는 설 문지를 통하여 검사문항을 4 점 척도 $(0$ 점=전혀 비슷하지 않다, 1 점=비슷하지 않다, 2점=비슷하다, 3점=매우 비슷하다)에 따라 내용의 적절성을 평가하여 단어 수준, 구문 수준, 전체적인 내용 수준의 평균값을 산출하여 검증하였다. 그 결과, 과제의 내용타 당도는 $77.8 \%$ 로 나타났다. 자발화 과제는 일상적인 질문에 답 하는 것으로 진행되었으며 한국어와 영어의 질문은 내용이 동 일한 질문으로 구성하였다. 읽기 과제의 지문과 자발화 과제의
질문은 부록 1 에 제시하였다.

\section{3. 연구 절차}

본 연구에서의 대상자는 언어 경험과 능숙도에 대한 조사서 (LEAP-Q; Marian et al., 2007)를 작성한 뒤 실험에 참여하였다. 모든 실험은 소음이 없는 실험실 내부에서 진행하였다. 모두 동 일한 마이크를 사용하여 대상자의 음성을 수집하였으며 대상 자와 마이크의 간격은 $15 \mathrm{~cm}$ 로 통제하였다. 실험은 연구자가 제 시하는 지문을 읽는 과제와 일상적인 질문에 대해 답하는 자발 화 과제로 나누어 진행되었다. 모든 과제는 한국어와 영어로 각 각 한 번씩 진행되었으며, 제시 순서는 한국어-영어 순이었다. 읽기 지문은 모두 유인물의 형태로 실험 시작 시 제공하였으며 자발화 과제는 사전에 미리 질문의 내용을 제공하지 않도록 하 였다. 또한 발화 과제의 질문은 매 실험마다 각각 영어 및 한국 어로 구성된 두 가지 질문 중 임의로 선정하였다. 자발화 과제 시 자연스러운 대화 상황처럼 설정하기 위해 실험 전에 미리 연 구자와 대상자 간에 라포를 형성하는 시간을 가졌으며 연구자 는 대상자 맞은편에 앉아 눈을 마주치고 답변에 호응하는 등 대 상자의 자연스러운 반응을 유도하였다. 언어 능숙도에 대한 조 사서 작성 시간을 제외하고, 대상자별 평균 실험 소요시간은 10 15분이었다.

\section{4. 자료 수집 및 통계 처리}

실험 대상자의 음성은 소음이 없는 실험실 내부에서 수집하 였으며 대상자의 입과 $15 \mathrm{~cm}$ 떨어진 위치에 마이크(CMP-G7 USB COBRA, China)를 고정하여 녹음하였다. 녹음의 샘플링 속 도는 $44,100 \mathrm{~Hz}$ 로 설정하였으며 양자화는 $16 \mathrm{bit}$ 로 하였다. 녹음된 음성에서 기본주파수를 살펴보기 위해 Praat(Boersma \& Weenink, 2001)을 사용하였으며 스펙트로그램 상에서 발화샘 플의 $\mathrm{fO}$ 를 추출하였다. 읽기 과제의 평균 기본주파수는 대상자 가 한국어 및 영어 지문을 읽는 동안의 f0 평균값을 추출하였다. 이때 안정적인 발화의 fo 값을 분석하기 위해 문단의 앞 뒤 한 문장을 제외한 나머지 부분의 fo 평균값을 분석하였다. 자발화 과제의 평균 기본주파수는 과제 수행 시 대상자들에게 질문에 1 
분 이상 자연스럽게 답할 것을 요청하여 그 중 가장 안정적인 구 간 30초의 f0 평균값을 추출하였다. 발화 내 3 초 $(3,000 \mathrm{~ms})$ 이상 의 쉼이나 머뭇거림이 있을 시에는 해당 부분을 제외하여 분석 하였다. 그림 1 은 자발화 상황에서의 스펙트로그램 분석 화면 예 시이다.

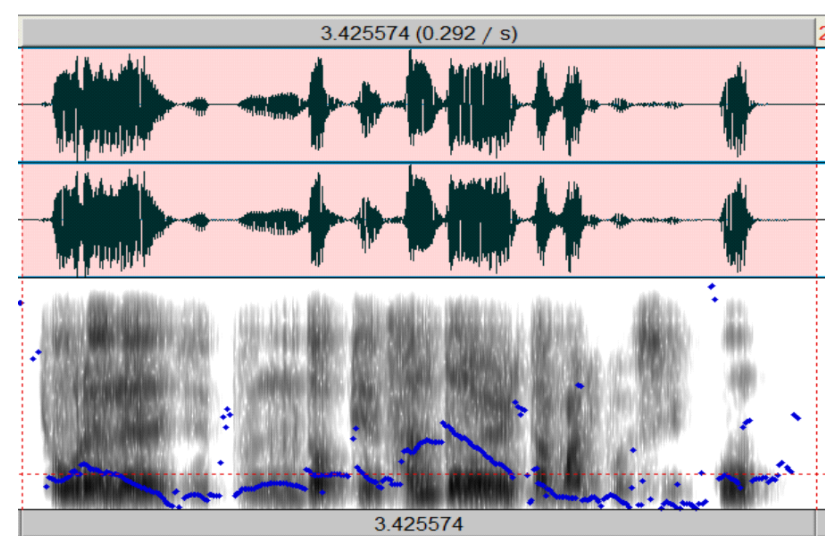

그림 1. 자발화 상황에서 스펙트로그램

Figure 1. Spectrogram on utterance

이후 각 성별 내 언어 $\times$ 과제 이원 배치분산 분석(two-way repeated ANOVA) 및 집단 $\times$ 언어 이원 혼합 분산 분석(two-way mixed ANOVA)을 실시하였다. 모든 통계분석은 SPSS(version 25.0) for windows를 사용하여 분석하였다.

\section{3. 연구 결과}

\section{1. 언어 및 과제에 따른 기본주파수 변화}

균형적 이중언어 집단의 한국어-영어의 읽기 및 자발화 과제 수행은 표 2에 제시하였다. 성별 간 기본주파수는 다르기 때문 에 과제 및 언어의 영향을 살펴보기 위해 각 성별 내에서 한국 어-영어 간 과제에 따라 평균 기본주파수에 차이가 있는지를 살 펴보았다.

그 결과, 여성의 경우 언어 $\left(F_{(1,13)}=13.804, p=.003\right)$ 및 과제 $\left(F_{(1,13)}=7.011, p=.020\right)$ 에 대한 주효과가 모두 유의하였다(그림 $2)$. 즉, 영어 $(M=199.07(\mathrm{~Hz}), S D=17.97)$ 보다 한국어 과제 $(M=$ $206.95(\mathrm{~Hz}), S D=17.50)$ 의 평균 기본주파수가 더 높았으며, 자발 화 과제 $(M=139.98(\mathrm{~Hz}), S D=19.76)$ 보다 읽기 과제 $(M=206.19(\mathrm{~Hz})$, $S D=15.80)$ 에서 기본주파수가 통계적으로 유의하게 높았다. 그 러나 언어와 과제 간 상호작용은 유의하지 않았다 $\left(F_{(1,13)}=.104\right.$, $p=.753)$. 반면, 남성의 경우 언어 $\left(F_{(1,13)}=.960, p=.345\right)$ 및 과제 $\left(F_{(1,13)}=3.339, p=.091\right)$ 에 대한 주효과와 언어 $\times$ 과제 간 상호작 용 $\left(F_{(1,13)}=.341, p=.569\right)$ 이 통계적으로 모두 유의하지 않았다(그 림 3).
표 2. 균형적 이중언어 집단의 읽기 및 자발화 과제의 기본주파수 Table 2. F0 mean of balanced bilinguals among reading and utterance tasks

\begin{tabular}{c|c|c|c|c|c}
\hline \multirow{2}{*}{ Variables } & \multicolumn{2}{|c|}{ Reading(Hz) } & \multicolumn{2}{c|}{ Utterance $(\mathrm{Hz})$} & \multirow{2}{*}{$F$} \\
\cline { 2 - 5 } & Korean & English & Korean & English & \\
\hline Women & 209.843 & 202.550 & 204.064 & 195.607 & \multirow{2}{*}{$13.804^{* *}$} \\
$(\mathrm{n}=14)$ & $(14.57)$ & $(17.23)$ & $(20.73)$ & $(19.31)$ & \\
\hline Men & 115.871 & 116.571 & 119.600 & 122.207 & \multirow{2}{*}{.906} \\
$(\mathrm{n}=14)$ & $(9.46)$ & $(10.80)$ & $(11.09)$ & $(14.65)$ & \\
\hline
\end{tabular}

Values are presented as mean $(S D)$.

Reading, reading task; Utterance, spontaneous utterance task. ${ }^{* *} p<.01$.

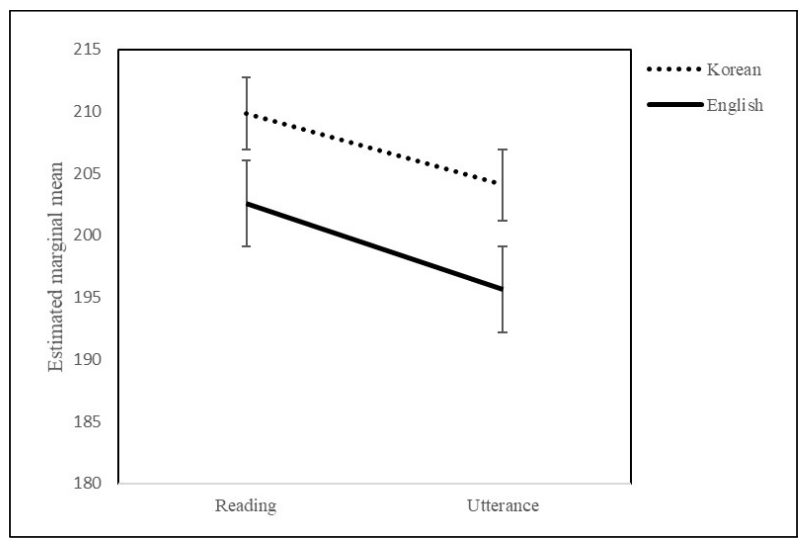

그림 2. 여성의 언어와 과제에 따른 기본주파수의 추정된 주변 평균 Figure 2. Female's estimated marginal mean of F0 across language and tasks

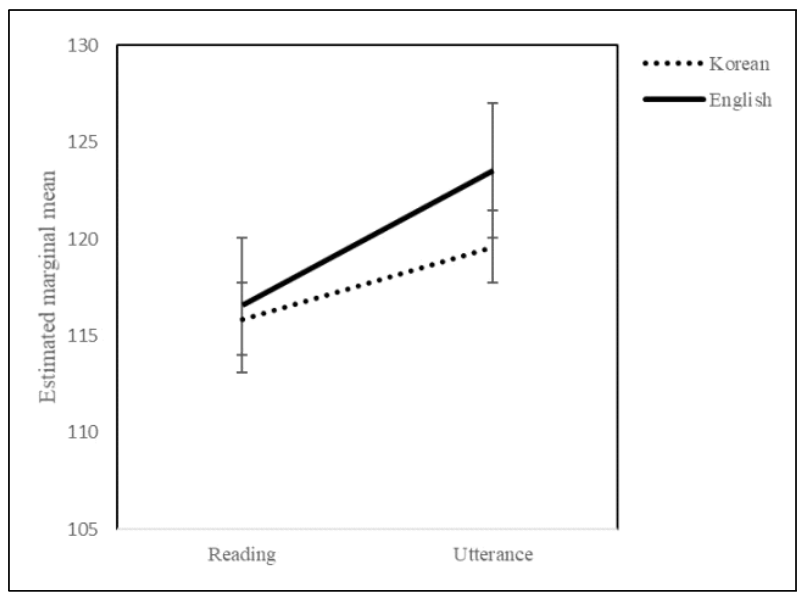

그림 3. 남성의 언어와 과제에 따른 기본주파수의 추정된 주변 평균 Figure 3. Male's estimated marginal mean of F0 across language and tasks

\section{2. 집단 간 언어에 따른 기본주파수 변화}

읽기 과제에서 언어 능숙도에 따라 집단 간(균형적 이중언어 집단, 한국어 우세 이중언어 집단) 평균 기본주파수에 차이가 있는지 알아보기 위해 읽기 과제에서의 언어 $\times$ 집단 간 이원혼 합 분산분석을 실시하였다. 첫 번째 연구 질문에 대한 결과로 언어 간 음도변화양상이 과제에 상관없이 일정하게 나타났기 때문에 본 실험에서는 자발화 과제는 실시하지 않고 읽기 과제 에서의 집단 간 기본주파수를 비교하였다. 


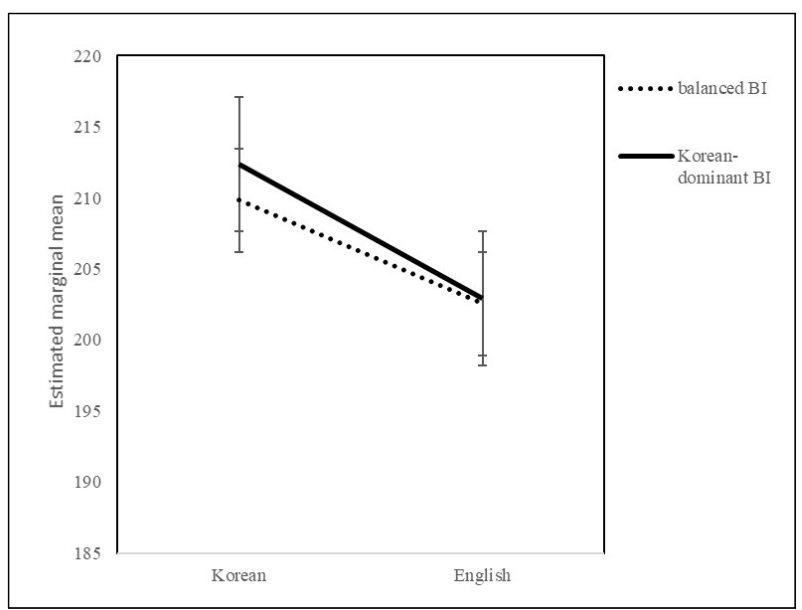

그림 4. 여성의 언어와 집단에 따른 기본주파수의 추정된 주변 평균 Figure 4. Female's estimated marginal mean of F0 across language and tasks

그 결과, 여성 대상자들의 언어에 대한 주효과 $\left(F_{(1,22)}=36.886\right.$, $p=.000$ )가 유의하였다(그림 4). 즉, 한국어 읽기 과제에서 평균 기본주파수 $(M=201.892(\mathrm{~Hz}), S D=15.53)$ 가 영어 읽기 과제 $(M=$ 202.713(Hz), $S D=16.70)$ 보다 유의하게 높았다. 그러나 집단에 대 한 주효과는 유의하지 않아 $\left(F_{(1,22)}=.047, p=.830\right)$ 언어 능숙도에 따른 평균 기본주파수의 변화는 없는 것으로 나타났다. 또한 언 어 $\times$ 집단 간 상호작용은 유의하지 않았다 $\left(F_{(1,22)}=.598, p=.448\right)$. 반면 남성의 경우, 읽기 과제에서의 언어 $\left(F_{(1,22)}=3.868, p=.062\right)$ 및 집단 $\left(F_{(1,22)}=.966, p=.336\right)$ 의 주효과가 모두 유의하지 않았으 며, 상호작용 또한 유의하지 않은 것으로 나타났다 $\left(F_{(1,22)}=1.977\right.$, $p=.174)$. 각 집단 간 읽기 과제의 평균 기본주파수는 표 3 에 제시 하였다.

표 3. 집단 간 읽기 과제의 수행

Table 3. Group performances of reading task

\begin{tabular}{c|c|c|c|c}
\hline Gender & Group & Korean(Hz) & English(Hz) & $F$ \\
\hline \multirow{4}{*}{ Women } & $\begin{array}{c}\text { Balanced BI } \\
(\mathrm{n}=14)\end{array}$ & $\begin{array}{c}209.843 \\
(14.57)\end{array}$ & $\begin{array}{c}202.550 \\
(17.23)\end{array}$ & \multirow{2}{*}{$36.886^{* *}$} \\
\cline { 2 - 4 } & $\begin{array}{c}\text { Korean } \\
\text { dominant BI } \\
(\mathrm{n}=10)\end{array}$ & $\begin{array}{c}212.360 \\
(17.48)\end{array}$ & $\begin{array}{c}202.940 \\
(16.85)\end{array}$ & \\
\hline \multirow{5}{*}{ Men } & $\begin{array}{c}\text { Balanced BI } \\
(\mathrm{n}=14)\end{array}$ & $\begin{array}{c}115.871 \\
(9.46)\end{array}$ & $\begin{array}{c}116.571 \\
(10.80)\end{array}$ & \multirow{2}{*}{3.868} \\
\cline { 2 - 4 } & $\begin{array}{c}\text { Korean } \\
\text { dominant BI } \\
(\mathrm{n}=10)\end{array}$ & $\begin{array}{c}112.979 \\
(12.16)\end{array}$ & $\begin{array}{c}113.140 \\
(17.95)\end{array}$ & \\
\hline
\end{tabular}

Values are presented as mean $(S D)$.

Balanced BI, balanced bilinguals; Korean dominant BI, Korean dominant bilinguals. ${ }^{* *} p<.01$.

\section{4. 논의 및 결론}

본 연구에서는 한국어-영어 이중언어 화자가 각각의 언어를 사용할 때, 각 성별 내 언어 및 과제에 따라 평균 기본주파수에 서 차이를 보이는지 알아보고자 하였으며, 언어의 능숙도에 따
라 읽기 과제에서 언어 간 평균 기본주파수의 변화양상이 달라 지는지를 알아보고자 하였다.

연구 결과, 여성은 읽기 및 자발화 과제에서 모두 영어보다 한국어에서의 평균 기본주파수가 더 높은 것으로 나타난 반면, 남성의 경우에는 두 언어 간 통계적으로 유의한 기본주파수변 화를 나타내지 않았다. 다시 말해서, 여성 이중언어 화자는 영어 와 한국어를 말할 때에 언어 간 음도가 변화하였고, 남성은 음도 변화를 보이지 않아 성별에 따라 기본주파수의 변화 양상이 다 르게 나타난 것을 확인할 수 있었다. 이는 이중언어 화자들의 언어 간 기본주파수 변화양상이 성별에 따라 다르다는 선행연 구와도 일치하는 결과이다(Ordin \& Mennen 2017; Voigt et al., 2016). 이러한 각 성별 내 기본주파수 변화 양상에서 차이는 언 어가 가지고 있는 음운론적 기본 특성이나 해부-생리학적인 차 이로 인한 것이라기보다는 사회문화적인 요소가 영향을 주는 것으로 해석하는 것이 더 적합하다. 만약, 해부-생리학적인 차 이나 언어학적 특성 등이 반영되었다면 언어에 따른 기본주파 수변화가 남녀 모두에게 나타났어야 하기 때문이다.

또한, 여성 이중언어 화자는 자발화 과제보다 읽기 과제에서 더 높은 평균 기본주파수를 보였지만 남성의 경우에는 과제 간 유의한 변화를 나타내지 않았다. 즉, 여성은 언어 간에도 기본주 파수 변화를 보이는 동시에 읽기 및 자발화 과제에 따라서도 평 균 기본주파수가 변화한 반면, 남성의 경우에는 언어 및 과제 유형에 상관없이 비슷한 음도를 산출하는 것으로 나타났다. 이 는 Zraick et al.(2000)의 연구에서도 여성의 경우에만 과제 유형 에 따른 주파수 변화가 있었다고 보고한 것처럼, 과제 자체의 특 성보다는 상황에 맞게 목소리를 유연하게 변화시키는 여성의 성향 등이 과제 간 주파수 변화에 기여한다고 해석할 수 있다.

또한, 기존연구에서는 모국어에서 과제 유형(읽기, 자발화)별 기본주파수 변화를 살펴본 반면, 본 연구에서는 이중언어 화자 의 모든 언어에서 과제유형별 음도 차이가 발생하는지 살펴보 았다. 그 결과, 언어 및 과제유형(읽기, 자발화) 모두 기본주파수 를 변화시키는 요인이며 특히 이는 여성에게 민감하게 작용하 는 요인인 것으로 나타났다. 이러한 결과는 음향학적 차이를 만 드는 요인이 해부생리학적인 요인과 언어적 특징에 기인한 결 과가 아닌 사회문화적 요소에 대한 민감성에 기인한 것으로 해 석할 수 있다.

마지막으로, 본 연구에서는 한국어 및 영어의 능숙도가 이러 한 기본주파수 변화에 영향을 미치는 요인인지 살펴보고자 하 였다. 언어의 능숙도가 주파수 변화에 직접적인 영향을 미칠 것 으로 예상하였으나, 앞선 결과와 마찬가지로 여성 대상자들은 능숙도에 상관없이 한국어-영어 간 유의한 기본주파수 변화를 보였다. 남성의 경우에는 언어 간 약간의 기본주파수 변화를 보 이기는 하였으나 통계적으로 유의하지는 않았다. 따라서 첫 번 째 연구 질문에 대한 해석으로 제시했던 사회문화적 영향은 언 어적 능숙도에 상관없이 나타나는 것으로 생각된다.

본 연구에서의 제한점은 다음과 같다. 언어 노출 정도를 거주 년도로 한정했으며 언어별 능숙도 또한 자기보고식 평가로 직 접평가가 아닌 간접평가를 통해 측정하였다. 그리고 본 연구 
를 일반화하기에는 다소 대상자 수가 적다는 한계점이 있다. 이 에 후속연구에서는 대상자수를 더 확보하고 사회문화적 요인 을 세분화하여 기본주파수 변화와의 관계를 살피는 것이 필요 하다.

\section{References}

Andreeva, B., Demenko, G., Möbius, B., Zimmerer, F., Jügler, J., \& Oleskowicz-Popiel, M. (2014, September). Differences of pitch profiles in Germanic and Slavic languages. Proceedings of Fifteenth Annual Conference of the International Speech Communication Association (pp. 1307-1311). Singapore.

Awan, S. N., \& Mueller, P. B. (1996). Speaking fundamental frequency characteristics of white, African American, and Hispanic kindergartners. Journal of Speech, Language, and Hearing Research, 39(3), 573-577.

Barrett, K. C., Zahn-Waxler, C., \& Cole, P. M. (1993). Avoiders vs. amenders: Implications for the investigation of guilt and shame during toddlerhood? Cognition \& Emotion, 7(6), 481-505.

Boersma, P., \& Weenink, D. J. M. (2001). Praat: A system for doing phonetics by computer. Glot International, 5(9/10), 341-347.

Briley, D. A., Morris, M. W., \& Simonson, I. (2005). Cultural chameleons: Biculturals, conformity motives, and decision making. Journal of Consumer Psychology, 15(4), 351-362.

Busà, M. G., \& Urbani, M. (2011, August). A cross linguistic analysis of pitch range in English L1 and L2. Proceedings of 17th International Congress of Phonetic Sciences (ICPhS XVII) (pp. 380-383). Hong Kong.

Bussey, K., \& Bandura, A. (1999). Social cognitive theory of gender development and differentiation. Psychological Review, 106(4), 676-713.

Chen, S. H. (2005). The effects of tones on speaking frequency and intensity ranges in Mandarin and Min dialects. The Journal of the Acoustical Society of America, 117(5), 3225-3230.

Danziger, S., \& Ward, R. (2010). Language changes implicit associations between ethnic groups and evaluation in bilinguals. Psychological Science, 21(6), 799-800.

Deutsch, D., Le, J., Shen, J., \& Henthorn, T. (2009). The pitch levels of female speech in two Chinese villages. The Journal of the Acoustical Society of America, 125(5), EL208-EL213.

Dolson, M. (1994). The pitch of speech as a function of linguistic community. Music Perception: An Interdisciplinary Journal, 11(3), 321-331.

Eady, S. J. (1982). Differences in the F0 patterns of speech: Tone language versus stress language. Language and Speech, 25(1), $29-42$.

Eagly, A. H. (1978). Sex differences in influenceability. Psychological Bulletin, 85(1), 86.
Ellis, C., Kuipers, J. R., Thierry, G., Lovett, V., Turnbull, O., \& Jones,

M. W. (2015). Language and culture modulate online semantic processing. Social Cognitive and Affective Neuroscience, 10(10), 1392-1396.

Fucci, D. J., \& Lass, N. J. (1999). Fundamentals of speech science (1st ed.). Boston, MA: Allyn \& Bacon.

Graddol, D., \& Swann, J. (1983). Speaking fundamental frequency: Some physical and social correlates. Language and Speech, 26(Pt 4), 351-366.

Graham, C. (2014). Fundamental frequency range in Japanese and English: The case of simultaneous bilinguals. Phonetica, 71(4), 271-295.

Gussenhoven, C. (2004). The phonology of tone and intonation. Cambridge, UK: Cambridge University Press.

Hanley, T. D., Snidecor, J. C., \& Ringel, R. L. (1966). Some acoustic differences among languages. Phonetica, 14(2), 97-107.

Hollien, H., \& Shipp, T. (1972). Speaking fundamental frequency and chronologic age in males. Journal of Speech and Hearing Research, 15(1), 155-159.

Hollien, H., Hollien, P. A., \& de Jong, G. (1997). Effects of three parameters on speaking fundamental frequency. The Journal of the Acoustical Society of America, 102(5), 2984-2992.

Huston, A. C. (1983). Sex typing. In P. H. Mussen (Series Ed.) \& E. M. Hetherington (Eds.), Handbook of child psychology (pp. 387-467). New York, NY: Wiley.

Keating, P., \& Kuo, G. (2012). Comparison of speaking fundamental frequency in English and Mandarin. The Journal of the Acoustical Society of America, 132(2), 1050-1060.

Künzel, H. J. (1989). How well does average fundamental frequency correlate with speaker height and weight? Phonetica, 46(1-3), $117-125$.

Laver, J. (1980). The phonetic description of voice quality: Cambridge Studies in Linguistics. Cambridge, UK: Cambridge University Press.

Lim, S. B., Lee, G., \& Rhee, S.-C. (2016). Effect of language on fundamental frequency: Comparison between Korean and English produced by L2 speakers and bilingual speakers. Phonetics and Speech Sciences, 8(4), 15-22.

Marian, V., Blumenfeld, H. K., \& Kaushanskaya, M. (2007). The Language Experience and Proficiency Questionnaire (LEAP-Q): Assessing language profiles in bilinguals and multilinguals. Journal of Speech, Language, and Hearing Research, 50(4), 940-967.

Mennen, I., Schaeffler, F., \& Docherty, G. (2012). Cross-language differences in fundamental frequency range: A comparison of English and German. The Journal of the Acoustical Society of America, 131(3), 2249-2260.

Morrison, M. D., \& Gore-Hickman, P. (1986). Voice disorders in the elderly. The Journal of Olaryngology, 15(4), 231-234. 
Murry, T., Brown, W. S., Jr., \& Morris, R. J. (1995). Patterns of fundamental frequency for three types of voice samples. Journal of Voice, 9(3), 282-289.

Mysak, E. D. (1959). Pitch and duration characteristics of older males. Journal of Speech and Hearing Research, 2(1), 46-54.

Nevo, L., Nevo, C., \& Oliveira, G. (2015). A comparison of vocal parameters in adult bilingual Hebrew-English speakers. CoDAS, 27(5), 483-491.

Ogunnaike, O., Dunham, Y., \& Banaji, M. R. (2010). The language of implicit preferences. Journal of Experimental Social Psychology, 46(6), 999-1003.

Ohala, J. J. (1984). An ethological perspective on common crosslanguage utilization of F0 of voice. Phonetica, 41(1), 1-16.

Ohara, Y. (1999). Performing gender through voice pitch: A cross-cultural analysis of Japanese and American English. In U. Pasero \& F. Broun (Eds.). Wahrnehmung und Herstellung von Geschlecht (pp. 105-116). Wiesbaden, Germany: Westdeutscher Verlag.

Ordin, M., \& Mennen, I. (2017). Cross-linguistic differences in bilinguals' fundamental frequency ranges. Journal of Speech, Language, and Hearing Research, 60(6), 1493-1506.

Ryabov, R., Malakh, M., Trachtenberg, M., Wohl, S., \& Oliveira, G. (2016). Self-perceived and acoustic voice characteristics of Russian-English bilinguals. Journal of Voice, 30(6), 772.e1-772.e8.

Shrivastav, R., Yamaguchi, H., \& Andrews, M. (2000). Effects of stimulation techniques on vocal responses: Implications for assessment and treatment. Journal of Voice, 14(3), 322-330.

Traunmüller, H., \& Eriksson, A. (1995). The frequency range of the voice fundamental in the speech of male and female adults. Unpublished manuscript.

Van Bezooijen, R. (1995). Sociocultural aspects of pitch differences between Japanese and Dutch women. Language and Speech, 38(3), 253-265.

Van Dommelen, W. A., \& Moxness, B. H. (1995). Acoustic parameters in speaker height and weight identification: Sex-specific behaviour. Language and Speech, 38(Pt 3), 267-287.

Voigt, R., Jurafsky, D., \& Sumner, M. (2016). Between- and withinspeaker effects of bilingualism on F0 variation. In Interspeech 2016, 1122-1126.

Yamazawa, H., \& Hollien, H. (1992). Speaking fundamental frequency patterns of Japanese women. Phonetica, 49(2), 128-140.

Yuan, J., Ryant, N., \& Liberman, M. (2014, May). Automatic phonetic segmentation in Mandarin Chinese: Boundary models, glottal features and tone. Proceedings of the 2014 IEEE International Conference on Acoustics, Speech and Signal Processing (ICASSP) (pp. 2539-2543). Florence, Italy.

Zimmerer, F., Jügler, J., Andreeva, B., Möbius, B., \& Trouvain, J. (2014). Too cautious to vary more? A comparison of pitch variation in native and non-native productions of French and German speakers. Proceedings of the Speech Prosody 7 (pp. 1037-1041). Dublin, Ireland.

Zraick, R. I., Nelson, J. L., Montague, J. C., \& Monoson, P. K. (2000). The effect of task on determination of maximum phonational frequency range. Journal of Voice, 14(2), 154-160.

Zraick, R. I., Skaggs, S. D., \& Montague, J. C. (2000). The effect of task on determination of habitual pitch. Journal of Voice, 14(4), 484-489.

\section{- 윤소망 (Somang Yoon)}

이화여자대학교 언어병리학과 석사과정

서울특별시 서대문구 이화여대길 52

Tel: 02-3277-6720

E-mail: y_somang@naver.com

관심분야: 아동언어장애, 이중언어, 말장애

- 목소라 (Sora Mok)

이화여자대학교 언어병리학과 석사과정

서울특별시 서대문구 이화여대길 52

Tel: 02-3277-6720

E-mail: msora2134@gmail.com

관심분야: 아동언어장애, 이중언어, 말장애

\section{- 윤정선 (Jungseon Youn)}

이화여자대학교 언어병리학과 석사과정

서울특별시 서대문구 이화여대길 52

Tel: 02-3277-6720

E-mail: Jeoungsun2727@gmail.com 관심분야: 신경언어장애, 말운동장애, 말장애

\section{- 한지윤 (Jiyun Han)}

이화여자대학교 언어병리학과 박사과정

서울특별시 서대문구 이화여대길 52

Tel: 02-3277-6720

E-mail: jiyunhan.umd@gmail.com 관심분야: 이중언어, 아동언어장애

- 임동선 (Dongsun Yim) 교신저자

이화여자대학교 언어병리학과 부교수 서울특별시 서대문구 이화여대길 52

Tel: 02-3277-6720

E-mail: sunyim@ewha.ac.kr 관심분야: 이중언어, 아동언어장애 
1.1. 읽기 과제

[한국어]

고양이는 장난감을 던지고 굴리고 흔들어주면서 놀아주는 것이 가장 좋다고 한다. 장난감을 움직이며 하는 놀이는 고양이에게 실제 사냥을 하는듯한 긴장감과 즐거움을 주기 때문이다. 그러나 고양이가 손이나 발 등 신체를 물거나 공격하면 당장 놀이를 중단하고 장난감을 치운 뒤 다른 곳으로 가야 한다고 조언했다. 그 이유는 고양이가 체벌을 놀이의 일부로 여길 수 있기 때문 이다.

[영어]

Cellphones have only existed for twenty years. In the past decade, they have become so popular that almost all adults in developed countries now own a small portable phone. Modern phones can perform wide variety of functions, such as taking and sending photographs, playing music and games, and even surfing the Internet. Their main use, however, remains to be for voice calls and short text messaging. As prices of both phones and calls have come down in the past ten years or so, they have become much more affordable for young people.

1.2. 자발화 과제

\section{[한국어]}

주말에 뭐 하세요?

가본 곳 중에 어디가 제일 좋았어요?

[영어]

What do you do on the weekends?

Where is the best place you've ever been to? 


\title{
한국어-영어 이중언어 화자의 사용 언어, 문맥, 언어 능숙도에 따른 기본 주파수 변화*
}

\author{
윤 소 망·목 소 라·윤 정 선·한 지 윤·임 동 선 \\ 이화여자대학교 일반대학원 언어병리학과
}

\begin{abstract}
국문초록
본 연구에서는 영어-한국어 이중언어 화자의 평균 기본주파수를 분석하여 언어 및 과제에 따른 차이가 있는지 살 펴보고, 거주년수 및 언어 능숙도에 따라 언어 간 평균 기본주파수 상이한지 실펴보고자 하였다. 본 연구의 대상자 는 영어권 나라에 7 년 이상 거주한 한국어-영어 균형적 이중언어 집단 총 28 명(남녀 각각 14 명, 균형적 이중언어집 단), 언어 노출기간 및 언어 능숙도에 차이를 두기 위해 추가로 모집한 영어권 나라 거주년수 3년 이하인 한국어 우 세 이중언어 집단 총 20 명(남녀 각각 10 명, 한국어 우세 이중언어 집단)이다. 이들은 한국어와 영어로 읽기 및 자발 화 과제를 수행하였고 Praat을 통해 녹음한 음성파일의 평균 기본주파수를 분석하였다. 이후 각 성별 내 언어 $\times$ 과 제 이원 배치 분산 분석(two-way repeated ANOVA) 및 집단 $\times$ 언어의 이원 혼합 분산 분석(two-way mixed ANOVA)을 실시하였다. 그 결과, 언어 및 과제에 따라 균형적 이중언어 집단의 남녀 대상군 별로 상이한 결과가 나타났다. 여 성의 경우 한국어보다 영어의 평균 기본주파수가 유의하게 높았으며 $(p=.003)$, 자발화과제보다 읽기 과제에서 평균 기본주파수가 유의하게 높았다 $(p=.002)$. 그러나 남성의 경우, 어떠한 조건에서도 유의한 결과가 나타나지 않았다. 두 번째로, 언어 능숙도에 따른 집단 간 비교에서 여성 대상자들에서만 언어 간 기본주파수 변화가 통계적으로 유 의하게 나타났다 $(p=.000)$. 즉, 한국어 읽기 과제에서 평균 기본주파수가 영어 읽기 과제보다 유의하게 높았다. 그러 나 언어 능숙도에 따른 평균 기본주파수의 변화는 통계적으로 유의하지 않았다 $(p=.830)$. 남성 대상자의 경우는 어 떤 조건에서도 유의한 결과는 없었다. 결과적으로, 이중언어 화자의 언어 간 평균 기본주파수의 변화는 언어의 능 숙도와 관계없이 성별에 따라 상이하게 나타났으며 본 연구를 바탕으로 언어 간 평균 주파수의 차이가 해부생리학 적 요인이나 언어학적 요인보다도 사화문화적인 요인에 의한 것임을 생각해 볼 수 있도록 한다.
\end{abstract}

핵심어: 이중언어, 언어 간 연구, 목소리 변화, 평균 기본주파수

* 본 연구는 2018년 교육부와 한국연구재단의 연구지원을 받아 수행되었음(과제번호: 2018S1A3A2075274). 